\title{
Spectrophotometric determination of chlorpheniramine maleate and phenylpropanolamine hydrochloride in dosage forms
}

\author{
*Arun Kaura1, Vikas Gupta1', G S Roy², Monika Kaura² \\ 1 University Institute of Pharmacy, Baba Farid University of Health Sciences, Faridkot, Punjab, India \\ 2B.I.S. College of Pharmacy, Gagra, Moga, Punjab, India
}

\begin{abstract}
A rapid and simple method for simultaneous determination of Chlorpheniramine Maleate (CPM) and Phenylpropanolamine Hydrochloride (PPM) by first derivative UV spectrophotometry has been developed in combined pharmaceutical dosage forms. The proposed method was successfully applied for the determination of drugs in physical mixture and commercial formulations and results showed good linearity, precision and reproducibility.
\end{abstract}

Key Words: Derivative, UV absorption, spectral overlap, principle maxima, wavelength range, analytical signal.

\section{INTRODUCTION}

Chlorpheniramine maleate $(\mathrm{CPM})$ inhibits the effects of histamine on capillary permeability and bronchial smooth muscles. It is an anti-allergic drug, widely used in cough-cold preparations. Phenylpropanolamine hydrochloride (PPM) is indirectly acting sympathomimetic agent and it is used in the symptomatic relief of nasal congestion. These drugs are used either alone or in combination. The simultaneous determination of these drugs is not possible by direct UV absorption measurement method because of spectral overlap of their principle maxima. The present work consists of taking a derivative of convenient order of the analytical signal i.e. absorbance in the wavelength domain. Besides the official methods (IP \& USP) the other analytical methods available in literature for determination of Chlorpheniramine Maleate (Alaa El-Gindy et al., 2005; Cieri et al., 2006; Fried et al., 2002; Liao et al., 2008; Marin et al., 2002; Rouhollah Heydari et al., 2008; Senyuva et al., 2002), Phenylpropanolamine Hydrochloride (Abbasi et al., 2006; Azhagvuel et al., 2007; Ferreyra et al., 2002; Issa et al., 2005; Kaddoumi et al., 2004; Nakashima et al., 2002) and combination of

\footnotetext{
*Corresponding Author:

Arun Kumar Kaura

University Institute of Pharmacy,

Baba Farid University of Health Sciences,

Sadiq Road, Faridkot-151203 (Pb.) India

E-mail: arunkaura70@rediffmail.com

Contact No.: +919888010178
}

Chlorpheniramine Maleate \& Phenylpropanolamine Hydrochloride (Fabrizio et al., 1980) have been mentioned. These methods are time consuming; therefore an alternative method for selective derivative UV spectrophotometry is rendered.

\section{MATERIALS AND METHODS}

\section{Materials}

Authentic specimens of CPM and PPM were provided as a gift samples from M/S Plethico Pharmaceuticals, Indore. All other reagents used were of analytical grade.

Analysis of commercial tablets \& recovery studies Spectrophotometric analysis was carried out on a Shimadzu UV 160-A spectrophotometer in $1 \mathrm{~cm}$ matched quartz cells. The amplitudes were obtained directly from the display of the first derivative in the wavelength range 200-325 $\mathrm{nm}$ with the derivation interval $5 \mathrm{~nm}$ at a medium scan speed for determination of CPM and PPM. The standard calibration curves of both the drugs were prepared to ascertain that the drugs solutions obey the Beer's Law in the concentration range to be utilized for the preparation of mixed standards, it was found that both the drugs followed Beer's Law in the working range of concentrations i.e. $0-24 \mu \mathrm{g} / \mathrm{ml}$ for CPM and $0-450$ $\mu \mathrm{g} / \mathrm{ml}$ for PPM. The solutions of both the drugs were prepared in distilled water. 
Table 1: Statistical evaluation of linearity of standard solutions of PPM and CPM.

\begin{tabular}{cccc}
\hline Analyte & Slope & Intercept & $\begin{array}{c}\text { Coefficient of } \\
\text { Correlation }\end{array}$ \\
\hline PPM & 0.0010394 & -0.3131 & 0.999 \\
CPM & 0.0141781 & 0.0271 & 0.999 \\
\hline
\end{tabular}

PPM: indicates Phenylpropanolamine hydrochloride

CPM: indicates Chlorpheniramine maleate

The correlation among slope, intercept and coefficient of correlation were estimated for both the drugs using standard calibration curves for PPM and CPM. The results of statistical data are given in table 1 . An accurately weighed portion $(243.26 \mathrm{mg}$ ) of the powder (mixed contents of 20 tablets) equivalent to about $4 \mathrm{mg}$ of CPM and $25 \mathrm{mg}$ of PPM were transferred to a $100 \mathrm{ml}$ calibrated flask. $50 \mathrm{mg}$ of PPM standard drug was weighed and transferred to the same volumetric flask. $60 \mathrm{ml}$ of distilled water was added and drugs were dissolved by shaking vigorously for 10 minutes. The resultant solution was filtered in $100 \mathrm{ml}$ calibrated flask and volume was made upto mark with distilled water. The final solution was labeled to claim $40 \mu \mathrm{g} / \mathrm{ml}$ of CPM and $750 \mu \mathrm{g} / \mathrm{ml}$ of PPM. From this stock solution different dilutions were made such that it falls in the working range of concentrations i.e. $0-24 \mu \mathrm{g} / \mathrm{ml}$ for CPM and $0-450 \mu \mathrm{g} / \mathrm{ml}$ for PPM. These diluted solutions were directly subjected to spectrophotometric analysis.

To study the recovery of CPM and PPM, preanalysed tablet sample solutions were taken and to these solutions, different concentrations of standard drugs (CPM and PPM) were added. The resultant solutions were analysed by proposed first derivative UV spectrophotometric method. The results (table 2) were found to be accurate, precise and reproducible.

\section{RESULTS AND DISCUSSION}

The normal or zero order overlain absorption UV spectra of CPM $(40 \mu \mathrm{g} / \mathrm{ml})$ and PPM $(250 \mu \mathrm{g} / \mathrm{ml})$ in the 200-325 nm wavelength region (figure 1), PPM exhibited three absorption peaks and it showed

Table 2: (a) Statistical estimation of results of CPM and PPM in authentic, commercial and recovery studies samples (b) Variations in performed statistical analysis.

\begin{tabular}{|c|c|c|c|c|c|c|c|c|}
\hline \multirow[t]{2}{*}{$\begin{array}{l}\text { Type of } \\
\text { sample }\end{array}$} & \multicolumn{2}{|c|}{$\begin{array}{l}\text { Expected Concentration } \\
(\mu \mathrm{g} / \mathrm{ml})\end{array}$} & \multicolumn{2}{|c|}{$\begin{array}{c}\text { Found Concentration } \\
(\mu \mathrm{g} / \mathrm{ml})\end{array}$} & \multicolumn{2}{|c|}{$\%$ found } & \multicolumn{2}{|c|}{ Mean \% Found } \\
\hline & $\mathrm{CPM}$ & PPM & CPM & PPM & CPM & PPM & CPM & PPM \\
\hline \multirow{5}{*}{$\begin{array}{l}\text { Authentic } \\
\text { samples }\end{array}$} & 4 & 50 & 4.0829 & 50.0885 & 102.07 & 100.17 & 99.958 & 99.374 \\
\hline & 6 & 100 & 5.9065 & 98.2961 & 98.44 & 98.29 & & \\
\hline & 10 & 200 & 9.9183 & 200.0677 & 99.18 & 100.03 & & \\
\hline & 15 & 300 & 15.764 & 296.4829 & 100.50 & 98.82 & & \\
\hline & 20 & 400 & 19.9219 & 398.2545 & 99.60 & 99.56 & & \\
\hline \multirow{5}{*}{$\begin{array}{l}\text { Commercial } \\
\text { samples }\end{array}$} & 4 & 75 & 4.0308 & 76.8705 & 100.77 & 102.49 & 100.69 & 100.126 \\
\hline & 8 & 150 & 8.0427 & 146.5037 & 100.53 & 97.66 & & \\
\hline & 12 & 225 & 12.2108 & 226.8497 & 101.75 & 100.82 & & \\
\hline & 16 & 300 & 16.1706 & 301.8393 & 101.06 & 100.61 & & \\
\hline & 20 & 375 & 19.8698 & 371.4725 & 99.34 & 99.05 & & \\
\hline \multirow{4}{*}{$\begin{array}{l}\text { Recovery studies } \\
\text { samples }\end{array}$} & 10 & 150 & 10.1105 & 149.9799 & 101.10 & 99.98 & 99.6075 & 100.07 \\
\hline & 4 & 125 & 3.9606 & 123.1972 & 99.01 & 98.55 & & \\
\hline & 6 & 100 & 5.9402 & 101.77 & 99.0 & 101.77 & & \\
\hline & 3 & 75 & 2.9797 & 74.9896 & 99.32 & 99.98 & & \\
\hline
\end{tabular}

(a)

\begin{tabular}{ccccccc}
\hline \multirow{2}{*}{$\begin{array}{c}\text { Type of } \\
\text { sample }\end{array}$} & \multicolumn{2}{c}{ Standard Deviation } & \multicolumn{2}{c}{ Standard Error } & \multicolumn{2}{c}{ Coefficient of Variation } \\
\cline { 2 - 7 } & CPM & PPM & CPM & PPM & \multicolumn{1}{c}{ CPM } & PPM \\
\hline Authentic Samples & 1.2484 & 0.7184 & 0.5583 & 0.3213 & 1.2489 & 0.7229 \\
Commercial Samples & 0.7893 & 1.6459 & 0.3529 & 0.7360 & 0.7839 & 1.6437 \\
Recovery Studies Samples & 0.8713 & 1.1419 & 0.4356 & 0.5709 & 0.8747 & 1.1412 \\
\hline
\end{tabular}

PPM: indicates Phenylpropanolamine hydrochloride

(b)

CPM: indicates Chlorpheniramine maleate 


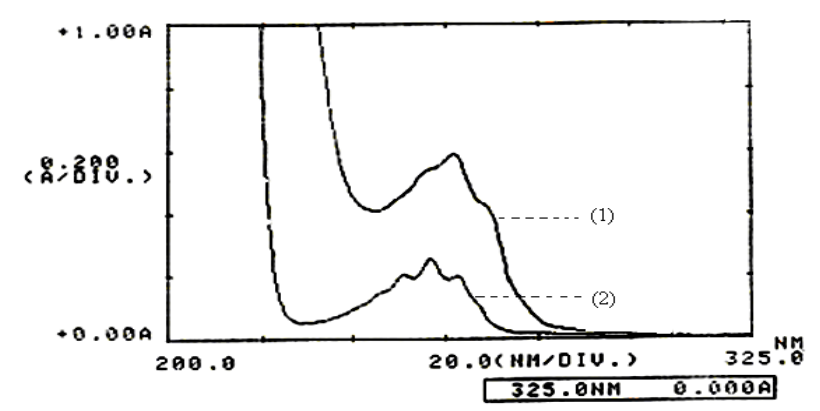

Figure 1: Normal and zero order overlain spectrum of CPM (1) and PPM (2).

maximum absorbance at $257 \mathrm{~nm}, \mathrm{CPM}$ also absorbed near this wavelength region with a peak at $261.6 \mathrm{~nm}$. The extensive overlap of spectral bands of these two drugs refrained conventional UV spectrophotometry for their individual determination in a mixture.

The first derivative spectra recorded the sharp bands of large amplitude of PPM $(250 \mu \mathrm{g} / \mathrm{ml})$ and CPM $(40 \mu \mathrm{g} / \mathrm{ml})$ (figure 2), which permitted very clear identification and determination of these drugs. The choice of the optimum wavelength is based on the fact that the contribution of one component to the overall derivative signal is zero at the wavelength at which the other component exhibited maximum absorption. From the first derivative overlain spectra of CPM and PPM (figure 2 ), it was found that at $231.4 \mathrm{~nm}$, PPM showed zero contribution. Therefore, this point was selected as zero crossing for PPM and at this point CPM showed remarkable absorbance. So, $231.4 \mathrm{~nm}$ was selected for CPM absorbance measurement and likewise $259.2 \mathrm{~nm}$ for PPM absorbance measurement for the simultaneous determination of CPM and PPM in a mixture form.

\section{CONCLUSION}

The derivative UV spectrophotometry appears to be a suitable technique for the reliable analysis of commercial formulations containing combination of CPM and PPM. The most striking features of the derivative method are its simplicity, sensitivity and rapidity. It is also an easier and economical method than HPLC separation technique and does not require the use of any expensive or toxic reagent. These advantages make it especially suitable for routine quality control.

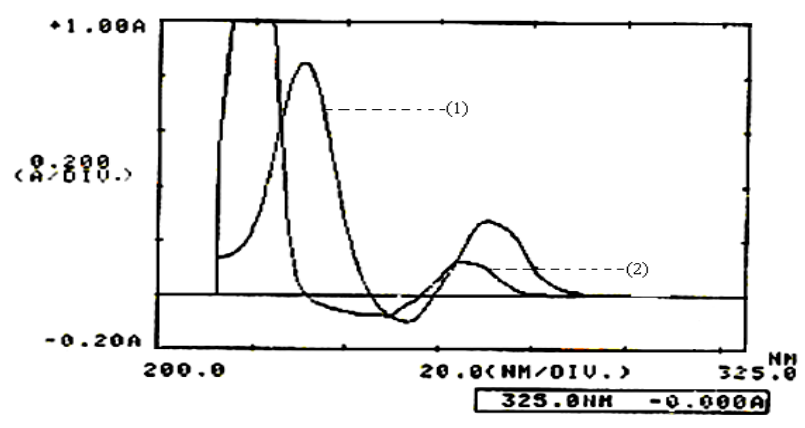

Figure 2: First derivative overlain spectrum of CPM (1) and PPM (2).

\section{ACKNOWLEDGEMENT}

The authors wish to thank the director, S.G.S.I.T.S., Indore and Head, Department of Pharmacy, Indore, for providing excellent research facilities for experimentation. The authors thank M/S Plethico Pharmaceuticals for providing drug samples.

\section{REFERENCES}

Abbasi K., Bhanger M.I., Khuhawar M.Y. (2006), Capillary gas chromatographic determination of phenylpropanolamine in pharmaceutical preparation, Journal of Pharmaceutical and Biomedical Analysis. 41(3): 998-1001. [DOI]

Alaa El-Gindy, Samy Emara, Mostafa Mesbah K., Ghada Hadad M. (2005), Liquid Chromatography and Chemometric-Assisted Spectrophotometric Methods for the Analysis of Two Multicomponent Mixtures Containing Cough Suppressant Drugs, Journal of AOAC International. 88(4): 1069-1080. PMid:16152922

Azhagvuel S., Sekar R. (2007), Simultaneous determination of Acetamiophen, cetrizine dihydrochloride, Phenylpropanolamine hydrochloride by capillary zone electrophoresis, Journal of Pharmaceutical and Biomedical Analysis. 43(3): 873-878. [DOI]

Cieri, Ugo R. (2006). Determination of Phenylephrine Hydrochloride, Chlor pheniramine Maleate, and Methscopolamine Nitrate in Tablets or Capsules by Liquid Chromatography with Two UV Absorbance Detectors in Series, Journal of AOAC International. 89(1): 53-57. PMid:16512228

Fabrizio De. (1980), Simultaneous GLC analysis of salicylamide, Phenylpropa-nolamine hydrochloride, caffeine, Chlorpheniramine maleate, phenylephrine hydrochloride, and pyrilamine maleate in capsule preparations, Journal of Pharmaceutical Sciences. 69: 854-855. [DOI]

Ferreyra C.F., Ortiz C.S. (2002), Simultaneous spectrophotometric determination of phenylpropanolamine HCL, 
caffeine and diazepam in tablets, Journal of Pharmaceutical and Biomedical Analysis. 29(5): 811-818. [DOI]

Fried K.M., Young A.E., Usdin Yasuda S. (2002), The enantioselective determination of chlorpheniramine and its major metabolites in human plasma using chiral chromatography on a beta-cyclodextrin chiral stationary phase and mass spectrometric detection, Journal of pharmaceutical and biomedical analysis. 27(3): 479-488. [DOI]

Issa Y.M., Youssef A.F., Mutair A.A. (2005), Conductimetric determination of phenylpropanolamine $\mathrm{HCl}$, ranitidine $\mathrm{HCl}$, hyoscyamine $\mathrm{HBr}$ and betaine $\mathrm{HCl}$ in their pure state and pharmaceutical preparations, Farmaco. 60: 541-546. [DOI]

Kaddoumi A., Mori T., Nakashima M.N., Wada M., Nakashima K. (2004), High performance liquid chromatography with fluorescence detection for the determination of phenylpropanolamine in human plasma and rat's blood and brain microdialysates using DIB-Cl as a label, Journal of Pharmaceutical and Biomedical Analysis 34: 643-650. [DOI]

Liao Q., Xie Z., Pan B., Zhu C., Yao M., Xu X., Wan J. (2008), LC-MS-MS simultaneous determination of paracetamol, pseudoephedrine and chlorpheniramine in human plasma: Application to a pharmacokinetic study, Chromatographia. 67(9-10): 687-694. [DOI]
Marin A., Garcia E., Garcia A., Barbas C. (2002), Validation of a HPLC quantification of acetaminophen, phenylephrine and chlorpheniramine in pharmaceutical formulations: capsules and sachets, Journal of Pharmaceutical and Biomedical Analysis. 29: 701-714. [DOI]

Nakashima K., Kanehara S., Kaddoumi A. (2002), HPLC determination of phenyl-propanolamine in pharmaceutical OTC preparations, Biomedical Chromatography. 16(7): 463-469. [DOI]

Rouhollah Heydari. (2008), a new HPLC Method for the Simultaneous Determination of acetaminophen, phenylephrine, Dextromethorphan and Chlorpheniramine in pharmaceutical Formulations, Analytical letters. 41: 965976. [DOI]

Senyuva H., Ozden T. (2002), Simultaneous highperformance liquid chromatographic determination of paracetamol, phenylephrine $\mathrm{HCl}$, and chlorpheniramine maleate in pharmaceutical dosage forms, Journal of Chromatographic Science. 40(2): 97-100. PMid:11881712 